\title{
EBSD Study of Damage Mechanisms in a High-Strength Ferrite-Martensite Dual-Phase Steel
}

\author{
N. Saeidi, F. Ashrafizadeh, B. Niroumand, and F. Barlat
}

(Submitted January 31, 2014; in revised form September 3, 2014; published online October 15, 2014)

\begin{abstract}
Electron backscattered diffraction (EBSD) analyses were performed on a fine-grained dual-phase (DP) sheet steel subjected to uniform tensile deformation and the preferred void nucleation sites as well as the micro-mechanisms of void formation were examined. EBSD study of grain average misorientation, grain orientation spread and kernel average misorientation of the deformed microstructure revealed that voids nucleation initially happened at ferrite-martensite interfaces neighboring rather large ferrite grains. This is believed to be mainly due to the higher shear deformation ability of the larger ferrite grains, the higher number of dislocation pile-ups at the martensite particles and the less uniform strain distribution within the larger ferrite grains compared to the smaller ones. The results demonstrated the impact of increasing uniform strain distribution within the DP microstructure on lowering the void nucleation probability.
\end{abstract}

Keywords dual-phase steel, EBSD analysis, void nucleation micro-mechanisms

\section{Introduction}

Ductile fracture of metals and alloys generally occurs through the following sequence: void nucleation, growth, and coalescence (Ref 1). Voids can be initiated either by the cracking of particles or the separation of particle/matrix interfaces (Ref 2-4). It has been shown (Ref 3) that in ferritepearlite microstructures, the formation of microcracks at cementite platelets in pearlite and the initiation of voids along well-developed dislocation cell walls in ferrite grains are the main void nucleation mechanisms. Since large variations in constituent particles morphology normally exist simultaneously in the engineering alloys, the nucleation behavior of voids is rather complicated and accordingly, each specific alloy system shows its characteristic behavior. Studying different martensite morphologies and their distribution in ferrite-martensite DP steels, Cingara et al. (Ref 5) showed that the uniform distribution of martensite particles within ferrite matrix discouraged void growth; however, it encouraged continuous void nucleation up to the final fracture. Also, they found that at strain values high enough to approach the fracture strain, the main population of voids was formed by the decohesion of ferritemartensite interfaces (Ref 6).

Void initiation between closely situated martensite particles along ferrite grain boundaries, in dual-phase steels, was also

N. Saeidi, F. Ashrafizadeh, and B. Niroumand, Department of Materials Engineering, Isfahan University of Technology, Isfahan 84156-83111, Iran; and F. Barlat, Materials Mechanics Laboratory (MML), Graduate Institute of Ferrous Technology (GIFT), Pohang University of Science and Technology (POSTECH), San 31 Hyojadong, Nam-gu, Pohang, Gyeongbuk 790-784, Republic of Korea. Contact e-mail: navidsae@gmail.com. observed by Kadkhodapour et al. (Ref 7). They ascribed this phenomenon to the strength mismatch between ferrite and martensite grains that made local stresses perpendicular to the loading direction. So, this led to the decohesion of ferrite-ferrite grain boundaries in the neighborhood of martensite grains and the creation of void starts from the early stages of deformation.

Moreover, it was shown that a coarse and interconnected martensite distributed along ferrite grain boundaries was prone to easily crack at lower strains followed by the decohesion of the ferrite-martensite interface at higher strains (Ref 6). In the case of a fine structure, martensite cracking was less frequent and void formation by ferrite-martensite interface separation was the dominant mechanism (Ref 8). Recently, the strain partitioning among the martensite and ferrite of DP steels has been directly measured and proved by in situ tensile tests coupled with digital image correlation or micro-grid techniques (Ref 9); it was found that the strain partitioning between the martensite and ferrite was a key factor controlling the void formation behavior in DP steels, depending mostly on the volume fraction and hardness of martensite particles.

Although the void nucleation mechanism by ferrite-martensite interface decohesion is well established, important parameters encouraging this kind of void initiation at specific regions have received less attention. In most cases, it has been simply stated (Ref 10,11 ) that void nucleation happens at martensite particles located at the ferrite grain boundaries, but the details of the process have not been clarified. In the present study, by using detailed SEM and EBSD analysis of tensile tested DP780 sheet steel specimens, void creation in a ferritemartensite DP microstructure was examined and its correlation with the ferrite grain size was identified.

\section{Materials and Methods}

DP780 sheet steel used in this research was provided by POSCO Company, South Korea. Tensile specimens were machined according to ASTM A370 standard (Ref 12) in the 
rolling direction (Fig. 1), using electrical discharge machining (EDM) method. The sheet thickness was about $1 \mathrm{~mm}$. The gage length was $50 \mathrm{~mm}$ and the tensile tests were performed at a constant cross-head speed of $1 \mathrm{~mm} / \mathrm{min}$ with a servo-hydraulic MTS machine. The deformed microstructures of the specimens were examined by a scanning electron microscope (SEM) equipped with an EBSD detector. The specimens were then sectioned through thickness along the mid-width in the longitudinal direction using Struers cutting machine. In order to measure local strains during deformation, these sectioned specimens were mounted, ground, and polished to 4000 grit finish and polished with 1-micron diamond suspension. The specimens were then polished using a colloidal silica suspension which slightly etched the surface of the material. Some other specimens were etched in $2 \%$ Nital solution. Characteristics of void features across the length of the specimen were then studied by SEM and EBSD. EBSD scans were performed on a TSL system mounted on a Zeiss ULTRA 55 microscope. Image quality (IQ), grain average misorientation (GAM), grain misorientation spread (GOS), and Kernel average misorientation (KAM) maps were mainly investigated by EBSD analysis. IQ value represents the sharpness of Kikuchi patterns at any given point. GAM value is an indication of the average neighbor-to-neighbor misorientation within the grains in the active partition. GOS value of a point indicates the orientation spread of the grain to which the point belongs. KAM value for each pixel is defined as the average misorientation that a pixel has with its neighbors ( 6 in our case), while boundaries with orientation difference over $5^{\circ}$ are recognized as grain boundaries. KAM value is an appropriate quantity used to evaluate the strain or the stored energy at a given point (Ref 13, 14).

\section{Results and Discussion}

The initial microstructure of the studied steel is presented in Fig. 1. As shown, the distribution of martensite particles was nearly uniform within the microstructure of DP780 steel and no noticeable banding could be observed. The yield strength of this steel was obtained to be equal to $550 \mathrm{MPa}$. Also, the ultimate tensile stress and failure strain were found to be $893 \mathrm{MPa}$ and 0.24, respectively (Fig. 2).

Detailed SEM observations showed that most initial voids were nucleated between closely spaced martensite particles (Fig. 3) located between rather two large ferrite grains. In other words, the area with the lower ratio or $\rho_{\mathrm{m}} / \rho_{\mathrm{f}}$, in which $\rho_{\mathrm{m}}$ is the local density of martensite particles and $\rho_{\mathrm{f}}$ is the local density of voids, is more susceptible to void creation. A straightforward analysis for the confirmation of this statement is to use the Quadrat method (Ref 15). A schematic representation of this method is shown in Fig. 4. For this analysis, multiple SEM micrographs, up to 10 micrographs and from the same strain value, were divided into a grid of square cells. Then, the number of martensite particles as well as voids in each cell was counted and divided by each cell area. So, the density of martensite particles and voids in different regions were measured. Consequently, the relative martensite occupation $\left(\rho_{\mathrm{r}}\right)$ for each cell was defined as $\rho_{\mathrm{r}}=\rho_{\mathrm{m}} / \rho_{\mathrm{f}}$. Cumulative analysis of relative martensite occupation data was conducted as presented in Fig. 5. It was evident that the frequency of occurrence in low values of $\rho_{r}$, i.e., the lower number ratio of martensite particles to the voids, was much higher than the other values. In other words, occurrence of void creation in areas with low density of martensite particles was more probable than the areas with high density of martensite particles.

In order to further explore this issue, EBSD analysis was performed on the deformed microstructure. Figure 6 shows image quality (IQ) map of the microstructure. Dark grains in the IQ map incorporated the martensite phase in which, due to the highly distorted lattice, Kikuchi patterns appeared faint or even invisible. Because of the absence of Kikuchi patterns, voids appeared very dark in this map; arrows in the IQ map indicated the voids. By the further processing of EBSD data, grain orientation spread (GOS) map, grain average misorientation (GAM) map, and Kernel average misorientation (KAM) map were also obtained. GAM map of the microstructure is presented in Fig. 7. It can be seen that this parameter was not so different within the constituent grains; it is also evident that GAM was nearly the same for grains surrounding the voids, such as grains shown as A and B (Fig. 7). According to KAM map (Fig. 8), the local misorientation at grain boundaries was higher than that within the grains. During uniaxial straining, the tendency toward localized inhomogeneous deformation due to

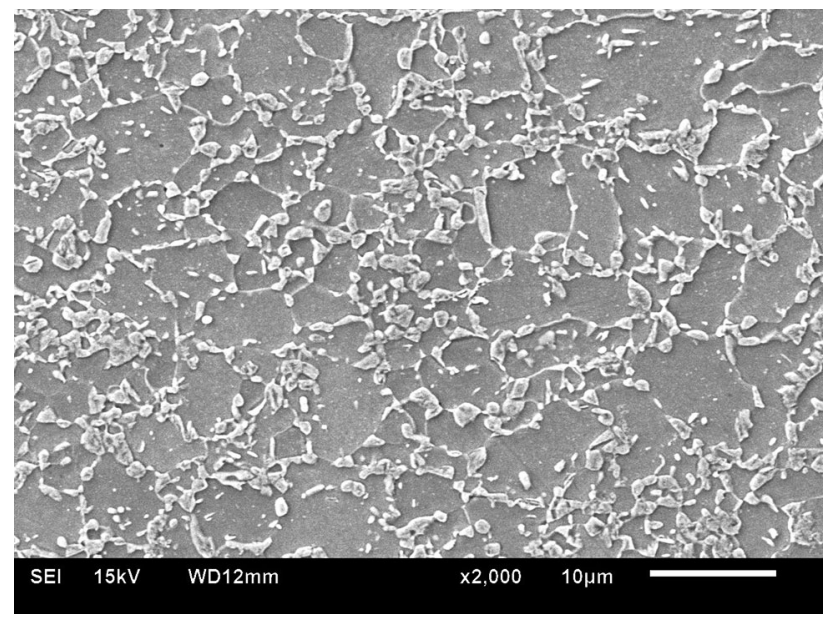

Fig. 2 Initial microstructure of DP780 steel

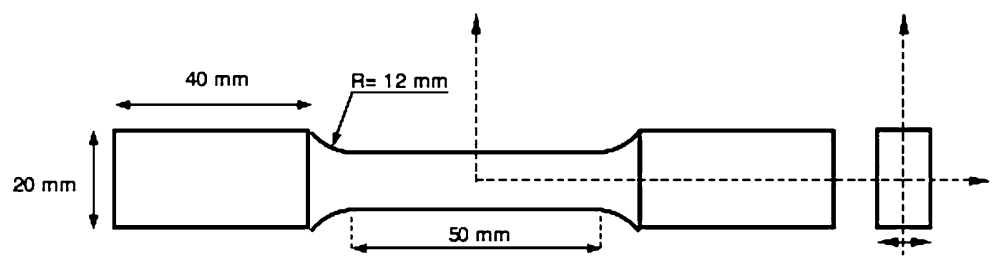

Fig. 1 Geometry of the tensile testing specimen 


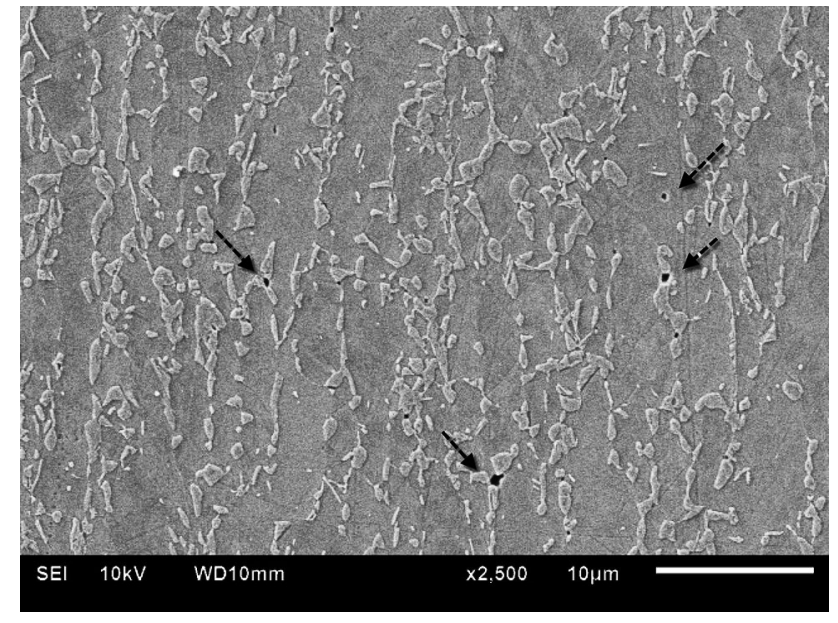

Fig. 3 Void nucleation between martensite particles located at the ferrite grain boundaries, by interface decohesion

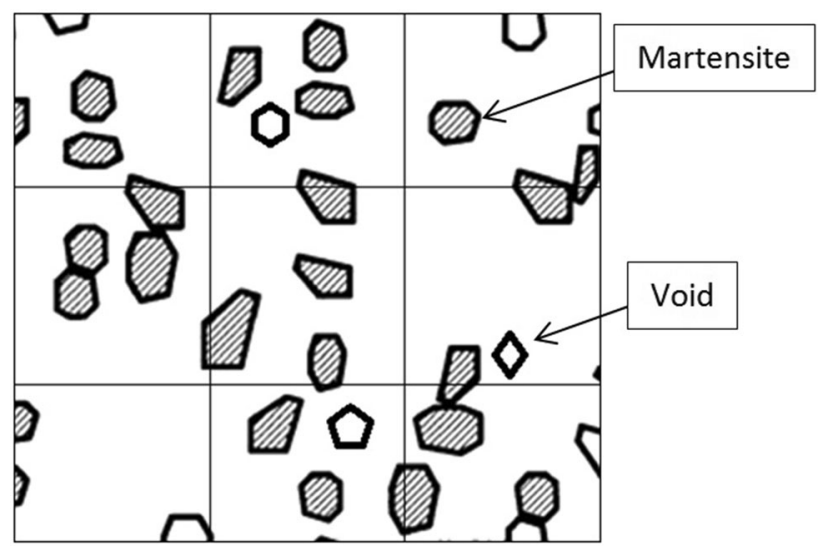

Fig. 4 Schematic presentation of Quadrat method analysis, the micrograph were divided by 9 cells, the voids as well as martensite particles was indicated with arrows

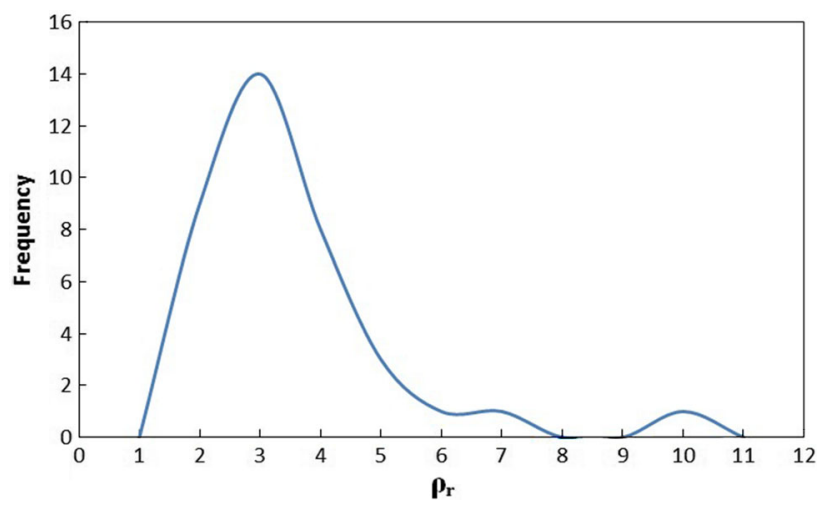

Fig. 5 Frequency distribution of relative martensite occupation $\left(\rho_{\mathrm{r}}\right)$

the different mechanical behavior of ferrite and martensite, as well as some restriction in shear deformation of ferrite grains by martensite particles, led to the creation of a high density of geometrically necessary dislocations, especially near the interface of ferrite and martensite (Ref 16,17$)$. So, in fine-grained

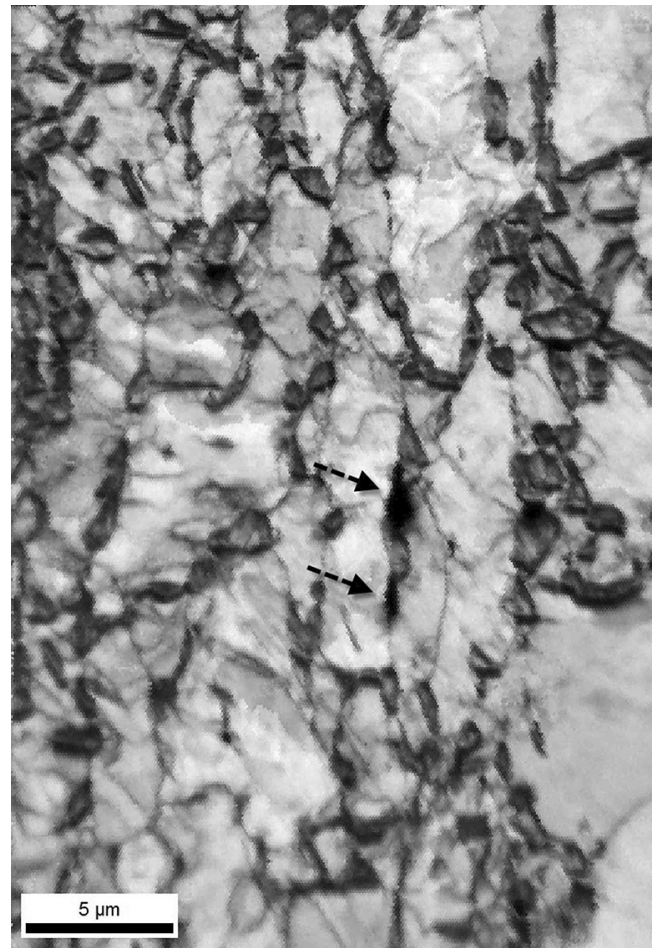

Fig. 6 IQ map of deformed microstructure

microstructures incorporating a high density of grain boundaries or interfaces, geometrically necessary dislocations should be higher within most parts of the grain. As a result, strain distribution would be more uniform within the grains in a finegrained microstructure than that in a coarse grained one. It can be said that the lesser the grain boundary to grain area ratio, the lower is the area fraction of the grain incorporating high KAM values; that is, area fraction of high KAM to low KAM values in large grains could be lower and consequently, GAM value of the grain would be lower in large ferrite grains than that of fine grains, as can be seen in Fig. 7. It is worth noting that strain distribution mentioned referred to the local strain within the microstructure. Owing to different strength properties of ferrite and martensite phases in a dual-phase steel, they could not be deformed uniformly during tensile test; therefore, immediately after yielding, the ferrite phase was deformed while martensite deformation would occur at higher strains and at a much lower rate. So, the strain distributions between ferrite and martensite grains would be inhomogeneous (Ref 7). It can be concluded that the higher density of geometrically necessary dislocations was created near the interfaces of ferrite and martensite particles (Ref 18).

In smaller ferrite grains (for example, grain $\mathrm{C}$ in Fig. 7), compared to the larger grains, a higher fraction of boundary was covered by martensite particles. Therefore, the restricting effect of hard martensite particles on the deformation of small ferrite grains was higher than that of the larger grains. On the other hand, as observed in the larger grains (for example, A and B in Fig. 7), shear deformation of these grains was less restricted by the surrounding martensite particles. Thus, the larger the ferrite grain size, the higher the shear deformation that could be sustained; therefore, in large grains, shear deformation bands can be observed in slightly etched specimens (Fig. 9). 

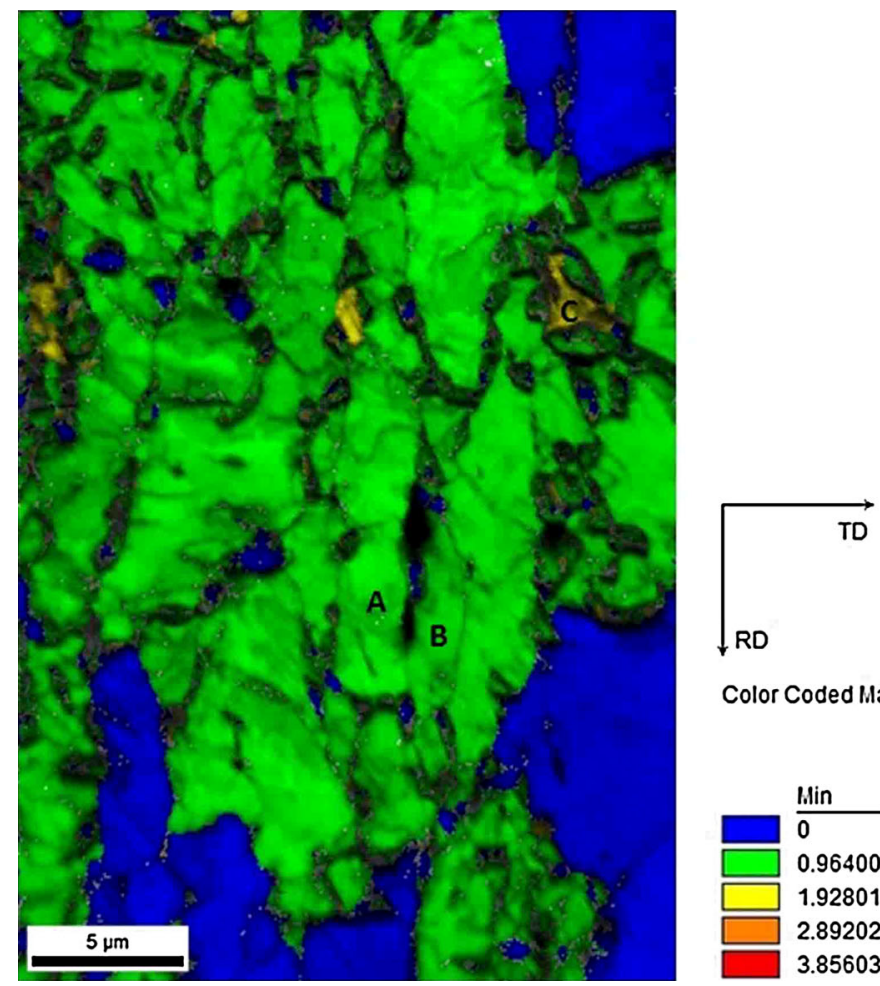

Color Coded Map Type: Grain Average Misorientation

\begin{tabular}{|c|c|c|c|}
\hline Min & Max & $\begin{array}{l}\text { Total } \\
\text { Fraction }\end{array}$ & $\begin{array}{l}\text { Partition } \\
\text { Fraction }\end{array}$ \\
\hline$\overline{0}$ & $\overline{0.964007}$ & $\overline{0.208}$ & $\overline{0.208}$ \\
\hline 0.964007 & 1.92801 & 0.704 & 0.704 \\
\hline 1.92801 & 2.89202 & 0.017 & 0.017 \\
\hline 2.89202 & 3.85603 & 0.001 & 0.001 \\
\hline 3.85603 & 4.82004 & 0.001 & 0.001 \\
\hline
\end{tabular}

Fig. 7 GAM map of deformed microstructure
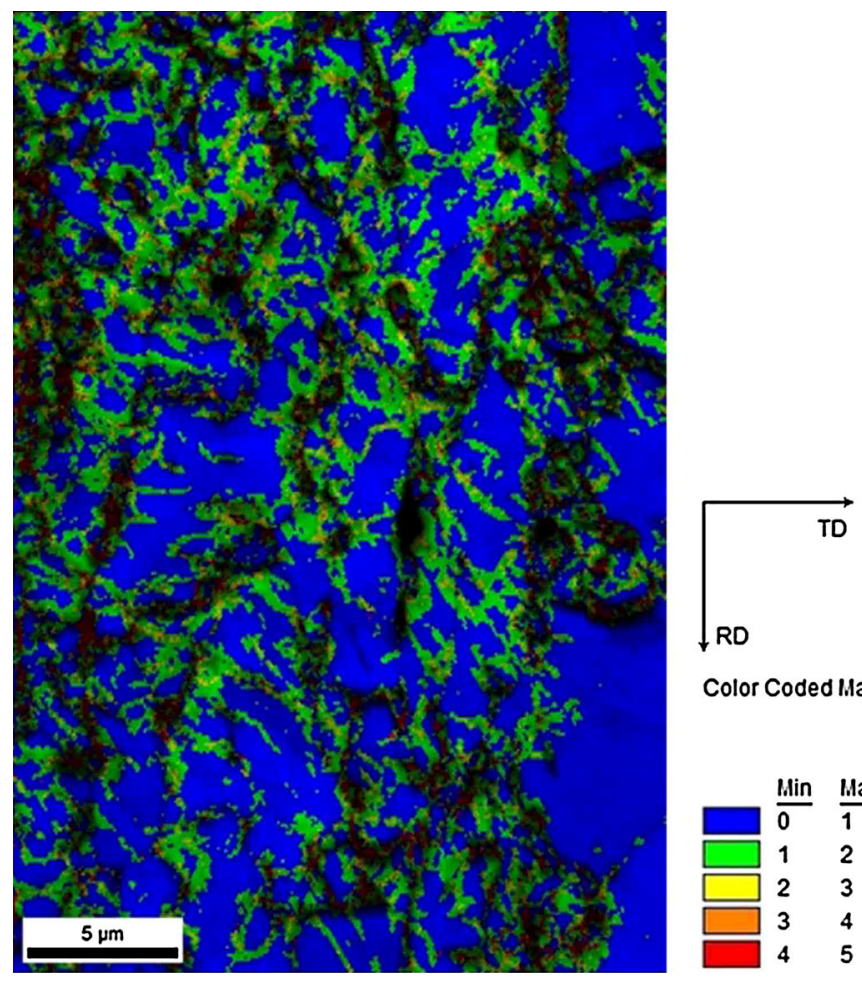

Color Coded Map Type: Kernel Average Misorientation

\begin{tabular}{|c|c|c|c|}
\hline Min & Max & $\begin{array}{l}\text { Total } \\
\text { Fraction }\end{array}$ & $\begin{array}{l}\text { Partition } \\
\text { Fraction }\end{array}$ \\
\hline$\overline{0}$ & $\overline{1}$ & $\overline{0.554}$ & $\overline{0.554}$ \\
\hline 1 & 2 & 0.304 & 0.304 \\
\hline 2 & 3 & 0.061 & 0.061 \\
\hline 3 & 4 & 0.009 & 0.009 \\
\hline 4 & 5 & 0.071 & 0.071 \\
\hline
\end{tabular}

Fig. 8 KAM map of deformed microstructure

GOS map (Fig. 10) shows that in grains having nearly the same GAM values (Fig. 7), there existed different orientation spreads, especially in grains A and B which surrounded the indicated voids in the map. The large grains of A and B had the same GAM value, but they showed different orientation spreads, GOS values. By considering GOS map (Fig. 10), it can be seen that there was more orientation spread in the larger grains compared to the smaller grains. GOS value could be an 
indication of strain distribution within the grain such that it could be expected that the lower orientation spread in a grain would result in better strain distribution within the grain. Better strain distribution within a small ferrite grain than a large ferrite grain could be justified by considering the constraint effect of the neighboring martensite particles on ferrite grains which imposed back stresses within the ferrite grain. It was shown that decreasing the grain size increased the back stress imposed by the stored dislocations at the dislocation emission points (Ref 19). Moreover, grain boundary martensite particles could accentuate the mentioned back stress (Ref 20). Therefore, it

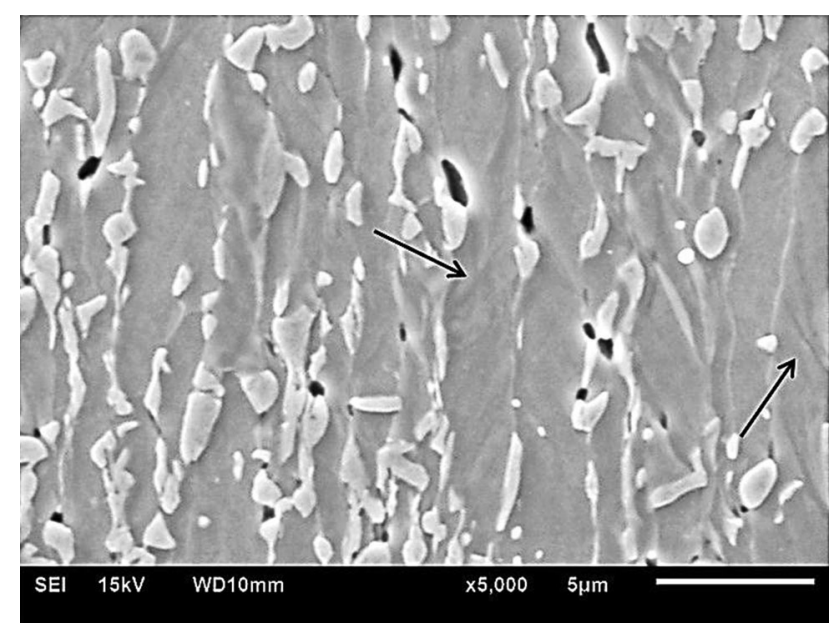

Fig. 9 Shear bands within large ferrite grains could be said that in the DP steel studied, the smaller the grain size, the higher the back stress created within the grain, per unit volume; therefore, the stress needed to generate successive dislocations from a given source was increased. As a consequence, in small grains, to continue the deformation, more dislocation sources should be activated. It was expected that the created dislocations from different sources would have a uniform distribution encouraging more uniform strain distribution within the smaller grains than the larger grains. This is consistent with a previous research (Ref 17) showing that with grain refinement in a ferrite-martensite DP steel, despite the increment of material strength, less severe stress/strain partitioning between ferrite and martensite would occur. This could lead to enhanced martensite plasticity and better interface cohesion that would increase the void nucleation resistance in these grains.

On the other hand, in large ferrite grains incorporating a lower amount of ferrite-martensite interfaces per unit volume, the mentioned back stresses would be lower (Ref 21); So, lower stresses needed to generate dislocations resulted in higher dislocation pile-ups within the large ferrite grain and a gradient of dislocations; therefore, the resulting misorientation from center toward the boundaries reached its maximum value at the boundaries (Ref 16). Therefore, the larger the grains size, the higher the stress concentration at martensite particles imposing higher shear stress at ferrite-martensite interface. As a result, a higher possibility of void nucleation would be expected in these regions, i.e., ferrite-martensite interfaces surrounded by large ferrite grains. Similarly, it was shown that (Ref 22) the larger the size of martensite particles, the higher the probability of their cracking. On the contrary, in a ferrite matrix composed of distributed fine martensite particles, martensite cracking was
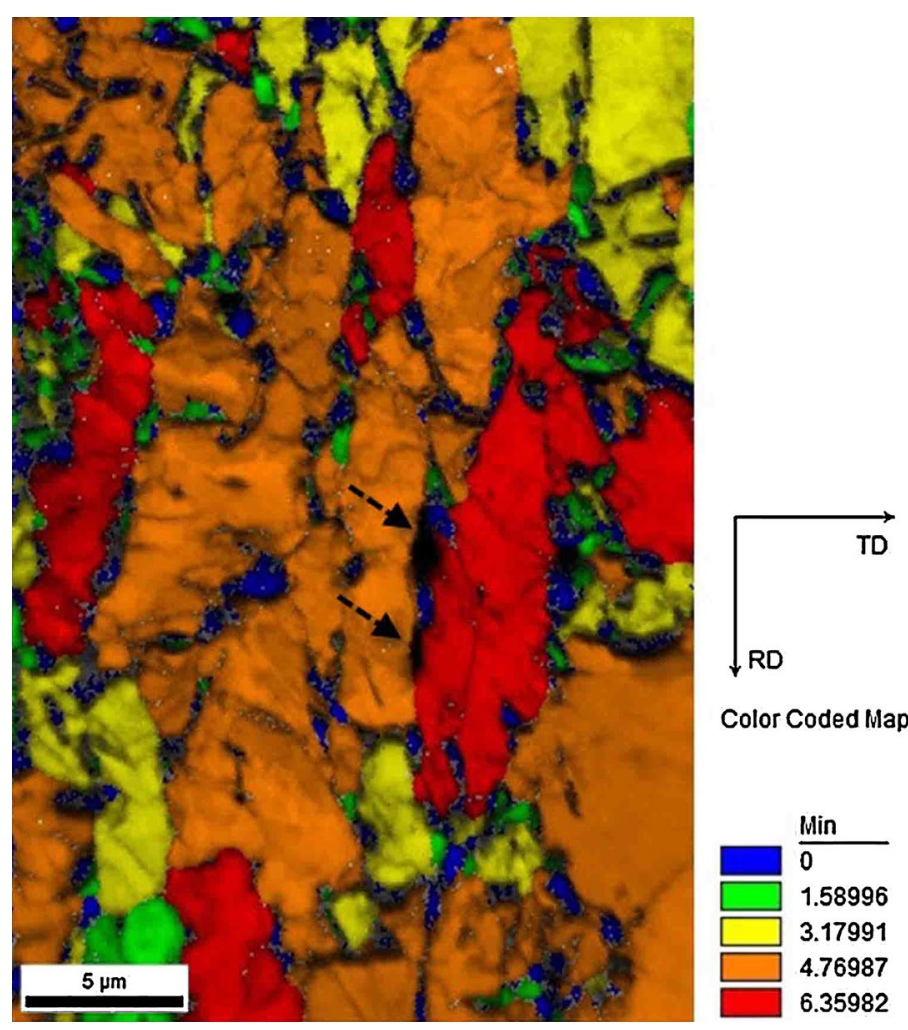

Color Coded Map Type: Grain Orientation Spread

\begin{tabular}{|c|c|c|c|}
\hline Min & Max & $\begin{array}{l}\text { Total } \\
\text { Fraction }\end{array}$ & $\begin{array}{l}\text { Partition } \\
\text { Fraction }\end{array}$ \\
\hline 0 & 1.58996 & 0.061 & 0.061 \\
\hline 1.58996 & 3.17991 & 0.055 & 0.055 \\
\hline 3.17991 & 4.76987 & 0.158 & 0.158 \\
\hline 4.76987 & 6.35982 & 0.485 & 0.485 \\
\hline 6.35982 & 7.94978 & 0.171 & 0.171 \\
\hline
\end{tabular}

Fig. 10 GOS map of deformed microstructure 
rare and the main void nucleation mechanism was the decohesion of ferrite- martensite interfaces.

To summarize, in a ferrite-martensite DP steel, the larger the ferrite grain size, or the lower the restricting effect of martensite particles surrounding a ferrite grain, the easier is the shear deformation and the creation of dislocation pile-ups within the ferrite grain. Consequently, strain distribution would be less uniform within the grain; this makes void formation easier at the interface of the larger ferrite grains compared to the smaller grains. It can be concluded that simultaneously decreasing both ferrite and martensite grain size leads to better strain distribution, lower void nucleation probability, and finally, higher void nucleation resistance within the DP microstructure.

\section{Conclusions}

In the present research, a high-strength structural steel, DP780, was mechanically tested under room temperature uniaxial tensile test condition. Detailed microstructural SEM and EBSD analysis revealed the mechanism of void nucleation. This can be summarized as follows:

1. The constraint effect of martensite particles on ferrite grains during deformation imposed rather pronounced back stresses within small ferrite grains, promoting more uniform strain distribution, lower GOS as well as higher GAM values within the smaller ferrite grains compared to the larger grains.

2. The constraint effect of martensite particles on ferrite grains during deformation resulted in lower shear deformation ability as well as less dislocation pile-ups in the smaller ferrite grains compared to the larger grains.

3. More uniform strain distribution and lower shear deformation ability as well as the lower number of dislocation pile-ups at the ferrite-martensite interfaces lowered the possibility of void nucleation in the smaller grains than that in the larger grains.

\section{References}

1. H. Jin, W.Y. Ln, J.W. Foulk, A. Mota, G. Johnson, and J. Korellis, An Examination of Anisotropic Void Evolution in Aluminum Alloy 7075, Exp. Mech., 2013, 53, p 1583-1596

2. J. Pospiech, Ductile Fracture of Carbon Steels: A Review, J. Mater. Eng. Perform., 1995, 4, p 82-89

3. J.K. Cuddy and M.N. Bassim, Ductile Fracture Mechanisms in AISI, 4340 Steel, Mater. Sci. Eng. A., 1990, 125, p 43-48
4. E. Ahmad, T. Manzoor, M.M.A. Ziai, and N. Hussain, Effect of Martensite Morphology on Tensile Deformation of Dual-Phase Steel, J. Mater. Eng. Perform., 2012, 21, p 382-387

5. G. Avramovic-Cingara, Y. Ososkova, M.K. Jain, and D.S. Wilkinson, Effect of Martensite Distribution on Damage Behavior in DP600 Dual Phase Steels, Mater. Sci. Eng. A., 2009, 516, p 7-16

6. G. Avramovic-Cingara, Y. Ososkova, M.K. Jain, and D.S. Wilkinson, Void Nucleation and Growth in Dual-Phase Steel 600 During Uniaxial Tensile Testing, Metall. Mater. Trans. A., 2009, 40, p 3117-3127

7. J. Kadkhodapour, A. Butz, and S. Ziaei Rad, Mechanisms of Void Formation During Tensile Testing in a Commercial, Dual-Phase Steel, Acta. Mater, 2011, 59, p 2575-2588

8. M. Calcagnotto, D. Ponge, and D. Raabe, Effect of Grain Refinement to $1 \mu \mathrm{m}$ on Strength and Toughness of Dual-Phase Steels, Mater. Sci. Eng. A., 2010, 527, p 7832-7840

9. X. Pan, X. Wu, K. Mo, X. Chen, J. Almer, J. Ilavsky, D.R. Haeffner, and J.F. Stubbins, Lattice Strain and Damage Evolution of 9-12\% Cr Ferritic/Martensitic Steel During In Situ Tensile Test by X-Ray Diffraction and Small Angle Scattering, Nucl. Mater, 2010, 407, p $10-15$

10. K. Kocatepe, M. Cerah, and M. Erdogan, The Tensile Fracture Behavior of Intercritically Annealed and Quenched Tempered Ferritic Ductile Iron with Dual Matrix Structure, Mater. Des., 2007, 28, p 172181

11. M. Sarwar, E. Ahmad, K.A. Qureshi, and T. Manzoor, Influence of Epitaxial Ferrite on Tensile Properties of Dual Phase Steel, Mater. Des., 2007, 28, p 335-340

12. Annual book of ASTM Standards, A370, 2001

13. K. Fujiyama, K. Mori, D. Kaneko, H. Kimachi, T. Saito, R. Ishii, and T. Hino, Creep Damage Assessment of 10Cr-1Mo-1W-VNbN Steel Forging Through EBSD Observation, Int. J. Pres. Ves. Pip., 2009, 86, p 570-577

14. K. Fujiyama, K. Mori, D. Kaneko, H. Kimachi, T. Saito, R. Ishii, and T. Hino, Creep-Damage Assessment of High Chromium Heat Resistant Steels and Weldments, Mater. Sci. Eng. A., 2009, 510-511, p 195-201

15. P.A. Karnezis, G. Durrant, and B. Cantor, Characterization of Reinforcement Distribution in Cast Al-Alloy/SiCp Composites, Mater. Charact., 1988, 40, p 97-109

16. N. Saeidi, F. Ashrafizadeh, B. Niroumand, and F. Barlat, Evaluation of Fracture Micromechanisms in a Fine Grained Dual Phase Steel During Uniaxial Tensile Deformation, J. Iron Steel Res. Int., 2014, 84, p 1386-1392

17. M. Calcagnotto, D. Ponge, and D. Raabe, Deformation and Fracture Mechanisms in Fine- and Ultrafine-Grained Ferrite/Martensite DualPhase Steels and the Effect of Aging, Acta. Mater, 2011, 59, p 658-670

18. J. Kadkhodapour, S. Schmauder, D. Raabe, S. Ziaei Rad, U. Weber, and M. Calcagnotto, Experimental and Numerical Study on Geometrically Necessary Dislocations and Non-homogeneous Mechanical Properties of the Ferrite Phase in Dual Phase Steels, Acta. Mater., 2011, 59, p 4387-4394

19. S. Lefebvre, B. Devincre, and T. Hoc, Yield Stress Strengthening in Ultrafine-Grained Metals: A Two-Dimensional Simulation of Dislocation Dynamics, J. Mech. Phys. Solids., 2007, 55, p 788-802

20. L. Zhonghua and G. Haicheng, Bauschinger Effect and Residual Phase Stresses in Two Ductile-Phase Steels: Part I. The Influence of Phase Stresses on the Bauschinger Effect, Metall. Trans. A., 1990, 21, p 717724

21. A.L. Helbert, X. Feaugas, and M. Clavel, Effects of Microstructural Parameters and Back Stress on Damage Mechanisms in $\alpha / \beta$ Titanium Alloys, Acta. Mater, 1998, 46, p 939-951

22. M. Erdogan and S. Tekeli, The Effect of Martensite Particle Size on Tensile Fracture of Surface-Carburised AISI, 8620 Steel with Dual Phase Core Microstructure, Mater. Des., 2002, 23, p 597-604 